\title{
The power of a picture
}

This month, we celebrate the beauty and power of microscopy images.

$\mathrm{n}$ this issue of Nature Methods, we've continued our yearly tradition of featuring the winner of Nikon's Small World Photomicrography Competition on our cover. This year's stunning winning image of a fluorescently labeled juvenile of the zebrafish, a common model organism, was captured using confocal microscopy and image-stacking by Daniel Castranova, assisted by Bakary Samasa, in Brant Weinstein's lab at the NIH. On this page, we highlight some of the other enchanting images that placed in the top 20 .

There is probably no tool used by biologists that is better known than the microscope. There is something truly magical about seeing something invisible to the naked eye for the first time. Tiny organisms, structures and cells can also be strikingly beautiful, containing both complex, repeating geometric patterns and wispy, watercolor-like impressions that come to light under the microscope.

The ever-growing toolbox of techniques and tools (many of which we've published in our pages) allow microscopists to take ever-more striking and informative images in fluorescent splendor. These intriguing photos of form help biologists understand function: there is no better way of understanding how nature works than by capturing a picture.

Published online: 29 October 2020 https://doi.org/10.1038/s41592-020-00997-1

A selection from the top 20 Small World contest winners. Top row: microtubules, captured by Jason Kirk, 7th place (left); marine diatom, captured by Jan Michels, 19th place (middle); clownfish embryos, captured by Daniel Knop, 2nd place (right). Second row: freshwater snail radula, captured by lgor Siwanowicz, 3rd place. Third row: hippocampal neurons, captured by Jason Kirk and Quynh Nguyen, 9th place (left); chameleon embryo, captured by Allan Carrillo-Baltodano and David Salamanca, 8th place (right). Bottom row: Atlas moth wing, captured by Chris Perani, 18th place (left); Hebe plant anther, captured by Robert Markus and Zsuzsa Markus, 6th place (right).
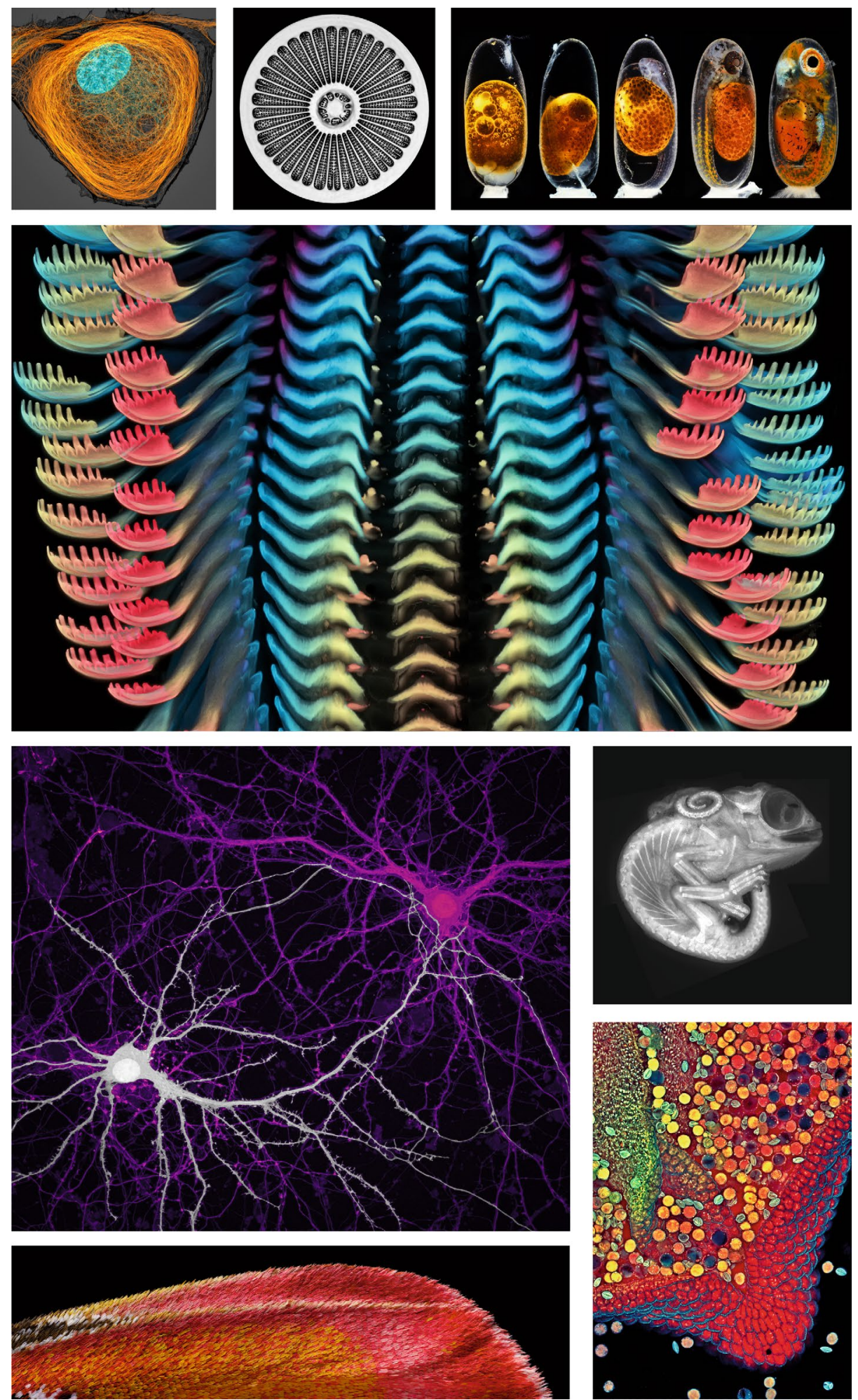